\title{
Preparation, characterization of Mo catalysts supported on Ni- containing calcium deficient hydroxyapatite and reactivity for the thiophene HDS reaction
}

\author{
A. Cherif, F. Hadhoudi, S. Ezzamouri and M. Lakhdar \\ Université Hassan II, Faculté des Sciences Aïn-Chock, BP. 5366, Mâarif Casablanca, Maroc
}

\begin{abstract}
Ni-containing Calcium Hydroxyapatite (NiCaHAp; 3.31 wt.\% Ni) was synthesized by coprecipitation and used as catalyst support. Molybdenum was supported on NiCaHAp by impregnation using ammonium heptamolybdate. The prepared catalysts $\mathrm{Mo}(\mathrm{x}) / \mathrm{NiCaHAp}$ (x: 2 to $8 \mathrm{wt} \%$ in Mo) were characterized by elemental analysis, XRD, FT-IR, $\mathrm{N}_{2}$ adsorptiondesorption and TEM-EDX. The catalysts were sulfided in-situ at $673 \mathrm{~K}$ under flowing $\mathrm{H}_{2} \mathrm{~S} / \mathrm{H}_{2}\left(15 \mathrm{Vol} \% \mathrm{H}_{2} \mathrm{~S}\right)$ and tested in hydrodesulfurization (HDS) of thiophene at $673 \mathrm{~K}$. The main XRD peaks of hydroxyapatite CaHAp phase were observed in all samples and a peak due probably to crystalline $\mathrm{MoO}_{3}$ phase was also identified from the results. However, no crystalline phase of $\mathrm{NiO}$ was found for the catalysts, which showed its $\mathrm{Ni}$ species were highly dispersed. The sulfided catalysts $\mathrm{Mo}(\mathrm{x}) / \mathrm{NiCaHAp}$ presented are active in HDS of thiophene, despite the presence of some large $\mathrm{MoO}_{3}$ crystallites and incomplete sulfidation. This activity may be due to interaction of $\mathrm{NiO}$ and $\mathrm{MoO}_{3}$ on CaHAp resulting in the formation of Ni-Mo-S phase under flowing $\mathrm{H}_{2} \mathrm{~S} / \mathrm{H}_{2}$. When the molybdenum content increased the HDS activity increasead slightly, which was caused by the agglomeration of $\mathrm{MoO}_{3}$. The $\mathrm{Mo}(8) / \mathrm{NiCaHAp}$ catalyst is about two times less active for thiophene HDS than the commercial $\mathrm{NiMoP} / \mathrm{Al}_{2} \mathrm{O}_{3}$.
\end{abstract}

\section{INTRODUCTION}

It is currently known that a great part of natural phosphates adopts a crystalline structure similar to that of synthetic hydroxyapatite $\mathrm{Ca}_{10}\left(\mathrm{PO}_{4}\right)_{6}(\mathrm{OH})_{2}$ [1]. The composition of natural phosphates is very complexe. Indeed, the apatitic lattice allows various anionic and cationic substitutions.

Despite their low cost and their availability in the market, the use and application of apatite in catalysis is still a subject of relatively scarce investigations. For example, calcium hydroxyapatite containing transition metals were found to be very active in the methane dry reforming [2], the hydrogenolyse of S-containing substrates [3], the propane oxidative dehydrogenation [4] and the epoxidation of olefin [5]

Within our research team, we have been looking for some new catalytic applications for apatitic compounds with a special interest for hydroxyapatite. Most of these studies are focused on the hydrodesulfurization (HDS) of petroleum distillate fractions for the reduction of atmospheric pollution due to the emission of hazardous compounds such as $\mathrm{SO}_{2}$.

Previously, we have shown that hydroxyapatite containing small amounts of carbonate species, with a $\mathrm{Ca} / \mathrm{P}$ molar ratio around 2 , can be used as a support for hydrodesulfurization sulfide catalysts since it exhibits the required textural properties and a good thermal stability [6].

In the present work, we studied the use of nickelcontaining calcium deficient hydroxyapatite Ni-CaHAp (3.31 wt \% Ni) prepared by coprecipitation at $\mathrm{pH}$ basic and calcined at $773 \mathrm{~K}$, as a support for molybdenum catalysts during the hydrodesulfurization of thiophene. Molydenum supported catalysts were prepared by impregnation using ammonium heptamolybdate $\left(\mathrm{NH}_{4}\right)_{6} \mathrm{Mo}_{7} \mathrm{O}_{24} \cdot 4 \mathrm{H}_{2} \mathrm{O}$.

The prepared catalysts were characterized using several experimental techniques such as X-ray diffraction,
FT-IR spectroscopy, nitrogen adsorption at $77 \mathrm{~K}$ and transmission electron microscopy combined with energydispersive X-ray analysis (TEM-EDX). Meanwhile, the hydrodesulfurization catalytic activity was assessed at atmospheric pressure using thiophene as a probe molecule.

\section{EXPERIMENTAL}

\subsection{Synthesis of catalysts}

\subsubsection{Synthesis of Ni-containing CaHAp}

The nickel-containing calcium hydroxyapatite (noted as NiCaHAp) precursor was synthesized using the following precipitation method: an ammoniacal solution of $\left(\mathrm{NH}_{4}\right)_{2} \mathrm{HPO}_{4}(\mathrm{~m}=11.75 \mathrm{~g}$ dissolved in $1000 \mathrm{ml}$ of distilled water $+100 \mathrm{ml}$ of $25 \%$ aqueous ammoniac) was poured into a second solution $(100 \mathrm{ml})$ of calcium nitrate $(m=18.51 \mathrm{~g})$ and nickel nitrate $(\mathrm{m}=5.75 \mathrm{~g})$ while stirring at $353 \mathrm{~K}$. The $\mathrm{pH}$ was maintained at 9 during mixing. After the dropwise addition $(3 \mathrm{~h})$, the mixture was kept at $353 \mathrm{~K}$ for $1 \mathrm{~h}$. After this time, the yellow solid was separated by filtration, washed with distilled hot water, dried overnight at $393 \mathrm{~K}$ and calcined at $773 \mathrm{~K}$. The $\mathrm{Ca} / \mathrm{P}$ atomic ratio of $\mathrm{Ni}-\mathrm{CaHAp}$ obtained was 1.51 indicating that the material is calcium deficient hydroxyapatite with a chemical formulae: Ni(3.31 wt $\%$ )$\mathrm{Ca}_{9.1}\left(\mathrm{HPO}_{4}\right)_{0.9}\left(\mathrm{PO}_{4}\right)_{5.1}(\mathrm{OH})_{1.1}$

\subsubsection{Synthesis of $\mathrm{Mo}(x) / \mathrm{NiCaHAp}$}

Molybdenum was loaded on the NiCaHAp by pore volume impregnation. Before impregnation, $2 \mathrm{~g}$ of the Ni-CaHAp was calcined under dry air flow, at $773 \mathrm{~K}$, for $2 \mathrm{~h}$, and then added to $1 \mathrm{~cm}^{3}$ of an aqueous solution of ammonium 
Table 1. Chemical composition, textural and structural characteristics of catalysts $\mathrm{Mo}(\mathrm{x}) / \mathrm{NiCaHAp}$.

\begin{tabular}{lcccccccc}
\hline & \multicolumn{3}{c}{ Chemical analysis } & \multicolumn{5}{c}{ Textural properties } \\
\cline { 2 - 9 } Catalysts & $\begin{array}{c}\mathrm{Ca} \\
\text { Wt.\% }\end{array}$ & $\begin{array}{c}\mathrm{P} \\
\text { Wt.\% }\end{array}$ & $\begin{array}{c}\mathrm{Ni} \\
\text { Wt.\% }\end{array}$ & $\begin{array}{c}\text { Mo } \\
\text { Wt.\% }\end{array}$ & $\begin{array}{c}\mathrm{Ca} / \mathrm{P} \\
\text { at./at. }\end{array}$ & $\begin{array}{c}\mathrm{S}_{\mathrm{BET}} \\
\left(\mathrm{m}^{2} / \mathrm{g}\right)\end{array}$ & $\begin{array}{c}\mathrm{Vp} \\
\left(\mathrm{cm}^{3} / \mathrm{g}\right)\end{array}$ & $\begin{array}{c}\mathrm{Dp} \\
(\mathrm{nm})\end{array}$ \\
\hline NiCaHAp & 35.74 & 18.35 & 3.31 & - & 1.51 & 114 & 0.56 & 20.0 \\
Mo(2)/NiCaHAp & 33.37 & 17.15 & 3.28 & 2.20 & 1.51 & 90 & 0.51 & 22.6 \\
Mo(5)/NiCaHAp & 32.48 & 16.93 & 3.24 & 4.62 & 1.49 & 83 & 0.48 & 23.2 \\
Mo(8)/NiCaHAp & - & - & 2.88 & 8.32 & - & 54 & 0.33 & 24.6 \\
\hline
\end{tabular}

heptamolybdate with the required concentration. The obtained slurry was left at room temperature for about one hour, and then evaporated at $333 \mathrm{~K}$. All the prepared catalysts were dried overnight at $393 \mathrm{~K}$ in an oven, and finally calcined at $773 \mathrm{~K}$ for $2 \mathrm{~h}$ under ambient atmosphere. All catalyst will be referred to as $\mathrm{Mo}(\mathrm{x}) / \mathrm{Ni}-\mathrm{CaHAp}$, were $\mathrm{x}$ (expressed in wt.\%) represents the weight percentage of Mo in the catalyst. The prepared catalysts contain loads varying from 2 to $8 \mathrm{wt} \%$ in molybdenum.

\subsection{Characterization techniques}

XRD patterns were obtained using a PW 1716 diffractometer, which utilizes $\mathrm{Ni}$-filtered $\mathrm{Cu}\left(\mathrm{K}_{\alpha}\right)$ radiation $(\lambda$ : $1.5405 \AA$ ). Samples were run as fine powders mounted on glass slides.

Fourier transform infrared spectroscopy (FT-IR) studies were carried out on the Vertex 70 spectrometer in the range $400-4000 \mathrm{~cm}^{-1}$. The transmission technique was applied and the samples were prepared as standard $\mathrm{KBr}$ pellets $(2 \%)$.

The textural properties of all the catalysts were carried out in an ASAP 2000 Micrometrics instrument by means of nitrogen adsorption and desorption at $77 \mathrm{~K}$. Before analysis, all the samples were evacuated at $573 \mathrm{~K}$ under vacuum.

The transmission electron microscopy (TEM-EDX) analyses were performed in a Tecnai $\mathrm{G}^{2}$-FEI operated at $120 \mathrm{KV}$. TEM specimens were prepared by depositing a few drops of catalysts dispersed in acetone on a carboncoated copper grid.

\subsection{HDS catalytic measurements}

The thiophene hydrodesulfurization reaction was carried out in a fixed bed flow reactor. Before the reaction, the oxide precursor $(50 \mathrm{mg})$ was pretreated at $773 \mathrm{~K}$ under ambient atmosphere, and then in-situ sulfided at $673 \mathrm{~K}$ under flowing $\mathrm{H}_{2} \mathrm{~S} / \mathrm{H}_{2}\left(15 \mathrm{Vol} . \% \mathrm{H}_{2} \mathrm{~S}\right)$ for $2 \mathrm{~h} 30 \mathrm{~min}$ at atmospheric pressure. Finally, the feed (thiophene $7.5 \mathrm{~mol} \%, \mathrm{H}_{2} \mathrm{~S} 2 \mathrm{~mol} \%$, and $\mathrm{H}_{2} 90.5 \mathrm{~mol} \%$ ) was supplied to the reactor and the HDS reaction was monitored at $673 \mathrm{~K}$ under atmospheric pressure. In these conditions, the total conversion of thiophene was kept below $15 \%$ to operate in differential regime. Thus, the catalytic activity could be estimated from the pseudo-first order rate constant $\mathrm{k}_{\mathrm{HDS}}$ :

$$
\mathrm{k}_{\mathrm{HDS}}=-(\mathrm{F} / \mathrm{CW}) * \operatorname{Ln}(1-\mathrm{X}) .
$$

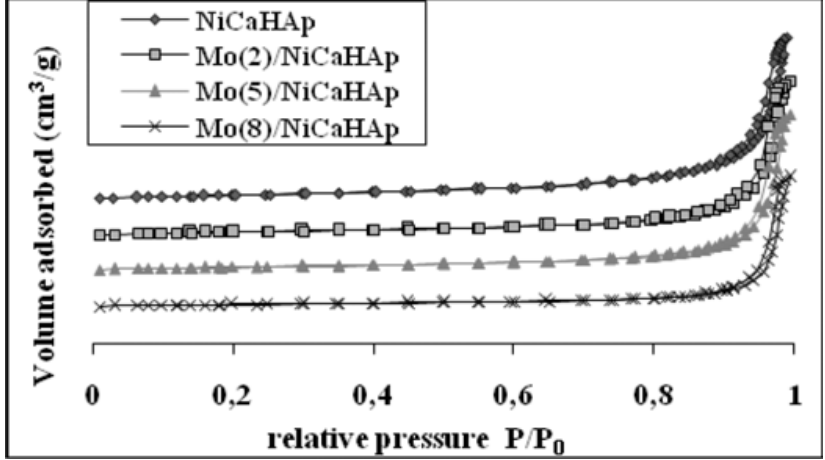

Figure 1. $\mathrm{N}_{2}$ adsorption-desorption isotherms of the Ni-CaHAp and the $\mathrm{Mo}(\mathrm{x}) / \mathrm{NiCaHAp}$.

Where $\mathrm{F}$ is the thiophene molar flow $(\mathrm{mol} / \mathrm{h}), \mathrm{W}$ is the weight of the sulfide catalyst ( $\mathrm{g}$ ), $\mathrm{X}$ is the total conversion of thiophene, and $\mathrm{C}$ the concentration of thiophene in the feed $(\mathrm{mol} / \mathrm{l})$.

The hydrodesulfurization reaction products were separated on a gas chromatograph (GC) using an OV1 column and analyzed with a thermal conductivity detector (TCD). Besides un-reacted thiophene, the reaction products are, $\mathrm{H}_{2} \mathrm{~S}$ and $\mathrm{C} 4$ (1-butene, trans-2-butene, cis2 - butane and butane). Thiophene conversion data were collected at 60 min intervals during 3 hours, and the values reported here are those obtained when the steady state is reached.

\section{RESULTS AND DISCUSSION}

\subsection{Characterization of catalysts}

\subsubsection{BET surface area and elemental analysis}

Table 1 summarizes the physicochemical parameters of the catalysts. Chemical analysis revealed a $\mathrm{Ca} / \mathrm{P}$ molar ratio ranging from 1.51 to 1.49 , compatible with calciumdeficient hydroxyapatite [7].

Figure 1 shows the $\mathrm{N}_{2}$ adsorption-desorption isotherms of the NiCaHAp and $\mathrm{Mo}(\mathrm{x}) / \mathrm{NiCaHAp}$ catalysts. All samples showed a type IV isotherm with a type H2 hysteresis loop, indicating the presence of well-developed mesoporosity in all the samples.

The BET surface area for NiCaHAp was $114 \mathrm{~m}^{2} / \mathrm{g}$. For the supported catalysts, an increase in molybdenum loading results in a decrease in the surface area probably due to pore blockage, since a similar pattern is observed for pore volume measurements (Table 1). There was a 


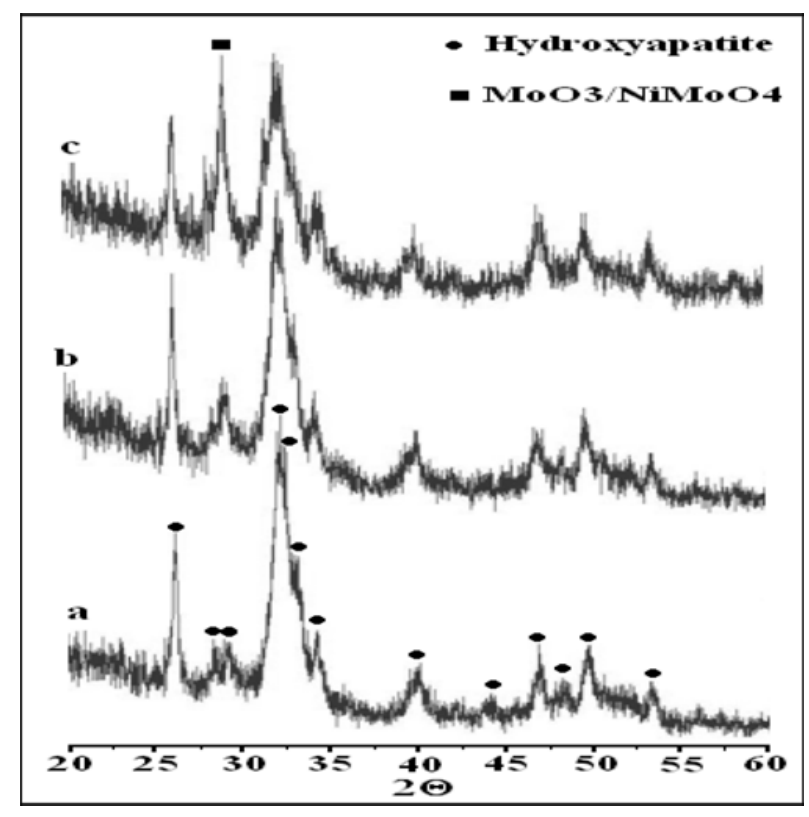

Figure 2. XRD patterns of NiCaHAp (a), Mo(2)/NiCaHAp (b) and $\mathrm{Mo}(8) / \mathrm{NiCaHAp}(\mathrm{c})$.

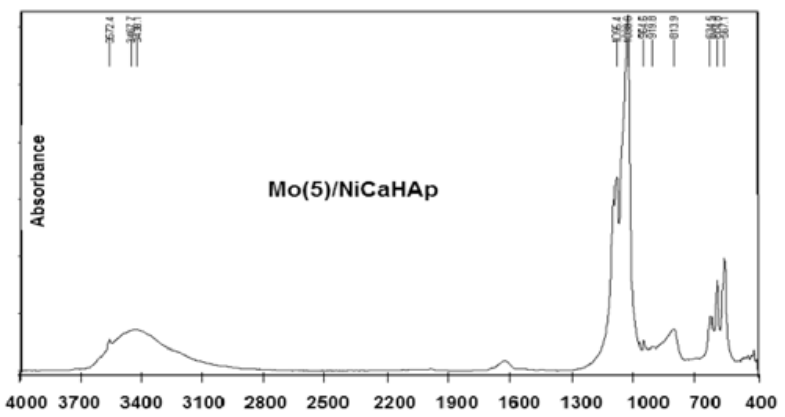

Wavenumber (cm-1)

Figure 3. Infrared vibration spectrum of the $\mathrm{Mo}(5) / \mathrm{NiCaHAp}$.

minimal increase of the pore diameter with an increase in the molybdenum loading.

It should be noted that the changes in pore volume, pore diameter and BET surface area decreased abruptly when the Mo exceeded 5wt.\%, which is attributed to the agglomeration of molybdenum oxide.

\subsubsection{Powder $X$-ray diffraction}

The powder XRD patterns of NiCaHAp and $\mathrm{Mo}(\mathrm{x}) /$ NiCaHAp catalysts in the angular range $2 \theta$ of $10-70^{\circ}$ are presented in Fig. 2. The NiCaHAp sample containing $3.31 \mathrm{wt} \% \mathrm{Ni}$ showed only diffraction lines belonging to calcium-hydroxyapatite CaHAp (JCPDS 090432), suggesting that the added nickel is amorphous and well dispersed on its surface. The diffraction peaks of CaHAp were clearly observed with all the $\mathrm{Mo}(\mathrm{x})$ /NiCaHAp catalysts. The diffraction peaks of CaHAp were weak, which was probably due to the small size of the particles [8]. Besides the peaks characteristic of calcium hydroxyapatite, we note the presence of a diffraction peak around $2 \theta \approx 29^{\circ}$ for high Mo loadings (8 wt.\% Mo). This

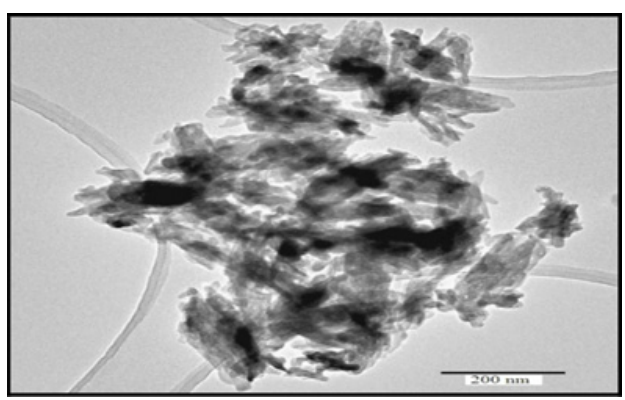

Figure 4. TEM image of the Mo(5)/NiCaHAp catalyst.

peak can be probably attributed to the presence of bulk $\mathrm{MoO}_{3}[9,10]$. Formation of a small amount of $\mathrm{NiMoO}_{4}$ (the strongest peak being at $2 \theta \approx 29^{\circ}$ ) is not excluded $[11,12]$.

\subsubsection{Infrared spectroscopy}

Figure 3 depicts the FT-IR spectrum of $\mathrm{Mo}(5) / \mathrm{NiCaHAp}$ catalyst, diluted in $\mathrm{KBr}(2 \%)$, in the $400-4000 \mathrm{~cm}^{-1}$ wavenumber range. We can see that the FT-IR spectra of the catalyst investigated here exhibit the presence of vibration bands characteristic of $\mathrm{OH}^{-}$groups (stretching mode at $3572 \mathrm{~cm}^{-1}$ and vibrational mode at $\left.634 \mathrm{~cm}^{-1}\right)$, $\mathrm{PO}_{4}^{3-}$ groups $\left(v_{3}: 1095\right.$ and $1040 \mathrm{~cm}^{-1}, v_{1}: 965 \mathrm{~cm}^{-1}, v_{2}$ : 605 and $567 \mathrm{~cm}^{-1}$ ) and the broads bands at $3435 \mathrm{~cm}^{-1}$ and at $1630 \mathrm{~cm}^{-1}$ were due to adsorbed $\mathrm{H}_{2} \mathrm{O}$. The bands assignments are according to literature data [13].

Meanwhile, we note the presence of a vibration band at $814 \mathrm{~cm}^{-1}$, which would correspond to the oxygen atom vibrations in Mo-O-Mo in which Mo represents hexavalent molybdenum [14].

\subsubsection{Transmission electron microscopy}

The micrograph of Mo(5)/NiCaHAp is shown in Fig. 4. Dark particles of metal oxide with a size distribution of 20-80 nm existed on the surface of CaHAp. EDX data show a Ni/Mo ratio of 1.07 which correlates with the value from elemental analysis (Table 1).

\subsection{Catalytic tests}

The thiophene hydrodesulfurization (HDS) model reaction has been used to establish the performance of the sulfided $\mathrm{Mo}(\mathrm{x}) / \mathrm{NiCaHAp}$ catalysts, $\mathrm{k}_{\mathrm{HDS}}$ values are plotted as a fonction of time on-stream (TOS) in Fig. 5. As can be seen, the sulfided $\mathrm{Mo}(\mathrm{x}) / \mathrm{NiCaHAp}$ catalysts, which initially display a high thiophene HDS activity, undergo a strong deactivation during the first hour. This behaviour is attributed to a loss of sulfur atoms from the active NiMoS phase during reaction with thiophene [15]. The $\mathrm{Mo}(\mathrm{x}) / \mathrm{NiCaHAp}$ catalysts show a much higher HDS activity than the sulfided NiCaHAp $\left(\mathrm{k}_{\mathrm{HDS}}=0.78 \mathrm{l} / \mathrm{hg}\right.$; $3.31 \mathrm{wt} \% \mathrm{Ni}$ ) and Mo/CaHAp ( $\mathrm{k}_{\mathrm{HDS}}=1.64 \mathrm{l} / \mathrm{hg} ; 2.1 \mathrm{wt} \%$ $\mathrm{Mo})$ catalysts, which is attributed to the promoting effect of $\mathrm{Ni}^{2+}$ ions in the mixed NiMo sulfided materials. 


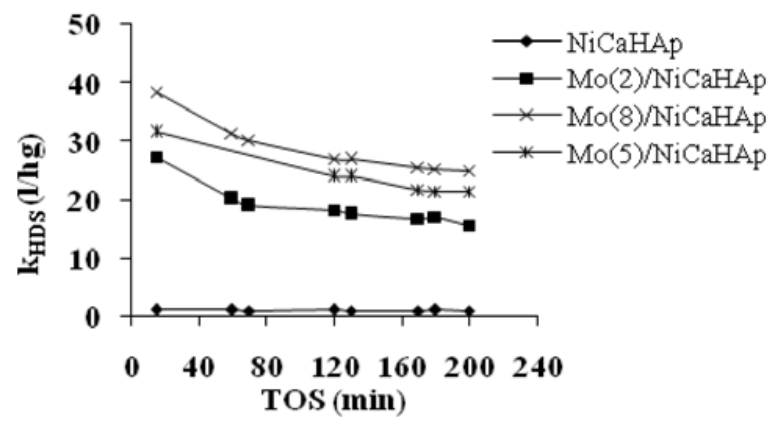

Figure 5. $\mathrm{k}_{H D S}$ of $\mathrm{Mo}(\mathrm{x}) / \mathrm{NiCaHAp}$ catalysts with TOS.

Table 2. Rate constants $\mathrm{k}_{\mathrm{HDS}}$ and degree of sulfidation $\mathrm{S} /(\mathrm{Ni}+$ Mo) of catalysts.

\begin{tabular}{lll}
\hline Catalysts & $\begin{array}{l}\mathrm{k}_{\mathrm{HDS}} \\
(1 / \mathrm{hg})\end{array}$ & $\begin{array}{l}\mathrm{S} /(\mathrm{Ni}+\mathrm{Mo}) \\
\text { at./at. }\end{array}$ \\
\hline $\mathrm{Mo}(2) / \mathrm{NiCaHAp}$ & 16.7 & 0.50 \\
$\mathrm{Mo}(5) / \mathrm{NiCaHAp}$ & 21.4 & 0.87 \\
$\mathrm{Mo}(8) / \mathrm{NiCaHAp}$ & 25.3 & 0.76 \\
$\mathrm{NiMoP} / \mathrm{Al}_{2} \mathrm{O}_{3}$ & 50.0 & - \\
\hline
\end{tabular}

It is worth noting that the activity of sulfided $\mathrm{Mo}(\mathrm{x}) / \mathrm{NiCaHAp}$ catalysts slightly increases with Mo loading, because the higher Mo loading will result in more and larger $\mathrm{MoO}_{3}$ particles and consequently the degree of sulfidation will be lower (Table 2). Among the catalysts tested, the Mo(5)/NiCaHAp catalyst showed better sulfidation than other catalysts. This may be due to a well dispersion of $\mathrm{MoO}_{3}$ particles on NiCaHAp (Table 2).

The HDS activity of $\mathrm{Mo}(8) / \mathrm{NiCaHAp}\left(\mathrm{k}_{H D S}=\right.$ $25.31 / \mathrm{hg} ; \mathrm{Ni} /(\mathrm{Ni}+\mathrm{Mo})=0.36)$ is lower than that of commercial $\mathrm{NiMoP} / \mathrm{Al}_{2} \mathrm{O}_{3}\left(\mathrm{k}_{H D S}=50 \mathrm{l} / \mathrm{hg} ; \mathrm{Ni} /(\mathrm{Ni}+\right.$ $\mathrm{Mo})=0.38)[10]$. Compared to the cited catalyst, the relatively lower activity of $\mathrm{Mo}(8) / \mathrm{NiCaHAp}$ catalyst is caused by the agglomeration of $\mathrm{MoO}_{3}$ particles.

\section{CONCLUSION}

The agglomeration of $\mathrm{MoO}_{3}$ and the incomplete sulfidation may explain the relatively low activity of the
$\mathrm{Mo}(\mathrm{x}) / \mathrm{NiCaHAp}$ catalysts in hydrodesulfurization of thiophene compared to the commercial $\mathrm{NiMoP} / \mathrm{Al}_{2} \mathrm{O}_{3}$ in the same experimental conditions.

\section{References}

[1] J.C. Eliot, in "Structure and Chemistry of the apatites and Other Calcium Orthophosphates", Elsevier, Amsterdam (1994).

[2] Z. Boukha, M .Kacimi, M.F.R. Pereira, J.L. Faria, J.L. Figueiredo, M. Ziyad, Appl. Catal. A: General. 317, 299 (2007).

[3] N. Elazarifi, A. Elouassouli, M. Lakhdar, A. Ezzamarty, J. Van Gestel, J. Leglise, Phosp. Res. Bull. 10, 430 (1999).

[4] M. Khachani, M. Kacimi, A. Ensuque, J. Piquemal, C. Connan, F. Bozon-Verduraz, M. Ziyad, Appl. Catal. A: General. 388, 113 (2010).

[5] C. Yuan, Y. Zhang, J. Chen, Chinese. J. Catal. 32, 1166 (2011).

[6] A. Cherif, A. Elouassouli, M. Lakhdar, A. Ezzamarty, J. Leglise, Ann. Chim. Mat. 25, 405 (2000).

[7] V.D.B.C. Dasireddy, S. Singh, H.B. Friedrich, Appl. Catal. A: General 421- 422, 58 (2012).

[8] S. Saoiabi, A. Laghzizil, K. Lahlil, A. Zrineh, J. Taiwan Inst. Chem. Eng. (2012), (to be published).

[9] S.I. Kim, S.I. Woo, J. Catal. 133, 124 (1992).

[10] N. Elazarifi, A. Elouassouli, M. Lakhdar, A. Ezzamarty, C. Moreau, A. Travert, J. Leglise, J. Phys. IV. France 123, 203 (2005).

[11] Z. Zhou, S-Li. Chen, D. Hua, A-C. Chen, Zhi-G. Wang, J-H. Zhang, J. Gao, Catal. Comm. 19, 5 (2012).

[12] L. Wang, W. Chu, C. Jiang, Yu. Liu, J. Wen, Z. Xie, J. Nat. Gas. Chem. 21, 43 (2012).

[13] M.N. Salimi, R.H. Bridson, L.M. Grover, G.A. Leeke, Powder Technology 218, 109 (2012).

[14] L.G. Pereira, A.S. Araujo, M.J.B. Souza, A.M.G. Pedrosa, M.R.C. Santos, I.M.G. Santos, L.E.B. Soledade, A.G. Souza, Mat. Lett. 60, 2638 (2006).

[15] B.M. Vogelaar, P. Steiner, T.F. van der Zijden, A.D. van Langeveld, S. Eijsbouts, J.A. Moulijn, Appl. Catal. A: General. 318, 28 (2007). 